Revista Brasileira de Informática na Educação - RBIE

Brazilian Journal of Computers in Education

(ISSN online: 2317-6121; print: 1414-5685)

http://br-ie.org/pub/index.php/rbie

\title{
Conceptual Map Creation from Natural Language Processing: a Systematic Mapping Study
}

\author{
Vinicius dos Santos \\ Federal Technological University of \\ Paraná - UTFPR \\ vinicius.dos.santos@usp.br \\ Willian Massami Watanabe \\ Federal Technological University of \\ Paraná - UTFPR \\ wwatanabe@utfpr.edu.br
}

\section{Érica Ferreira de Souza}

Federal Technological University of

Paraná - UTFPR

ericasouza@utfpr.edu.br

Nandamudi L. Vijaykumar

National Institute for Space Research INPE

vijay.nl@inpe.br

\author{
Katia Romero Felizardo \\ Federal Technological University \\ of Paraná - UTFPR \\ katiascannavino@utfpr.edu.br
}

Sandra Maria Aluizio

Instituto de Ciências Matemáticas e

Computação - USP

sandra@icmc.usp.br

\author{
Arnaldo Cândido Júnior \\ Federal Technological University of \\ Paraná - UTFPR \\ arnaldoc@utpfr.edu.br
}

\begin{abstract}
Context: Conceptual Maps (CMs) have been used to organize knowledge and facilitate learning and teaching in multiple domains. CMs are also used in multiple settings in education, since they are able to clarify the relationships between the subcomponents of a particular topic. However, the construction of a CM requires time and effort in identifying and structuring knowledge. In order to mitigate this problem, Natural Language Processing (NLP) techniques have been employed and have contributed to automate the extraction of concepts and relationships from texts. Objective: This article summarizes the main initiatives of building CMs from NLP. Method: A systematic mapping study was used to identify primary studies that present approaches on the use of NLP to automatically create CMs. Results: The mapping provides a description of 23 available articles that have been reviewed in order to extract relevant information on a set of Research Questions (RQ). From the answers to RQ, a classification scheme was designed in order to present how NLP could be employed to construct CMs. From this classification scheme, a graph was elaborated to present different paths to construct CMs using NLP. Conclusions: The construction of CMs using $N L P$ is still a recent topic, however, it has been proven to be effective in assisting the automatic construction of CMs.
\end{abstract}

Keywords: Concept Maps; Natural Language Processing; Knowledge Representation; Systematic Mapping Study.

Cite as: $\quad$ Santos, V, Souza, E. F., Felizardo, K. R.. Watanabe, W. M., Vijaykumar, N. L., Aluizio, S.M. \& Candido, A. (2019). Conceptual Map Creation from Natural Language Processing: a Systematic Mapping Study. Brazilian Journal of Computers in Education (Revista Brasileira de Informática na Educação - RBIE), 27(3), 150-176. DOI: 10.5753/RBIE.2019.27.03.150 


\section{Introduction}

Knowledge Management (KM) is pointed out as an important means to manage knowledge in companies or organizations. The main goal of KM is to promote knowledge storage, sharing as well as the emergence of new knowledge (O’Leary \& Studer, 2001). Managing knowledge is a key challenge for organizations and research institutions, since it can become a consistent intellectual component in the decision-making process (O’Leary \& Studer, 2001; Zack \& Serino, 2000; O'Leary, 1998). Among the strategies to understand and share knowledge, Concept Mappings (CMs) are considered as a useful graphical technique (Novak \& Cañas, 2008).

Originally CMs were proposed in education in order to enable students constructing representations of knowledge-based representation of concepts and their relationships. This representation has been considered as a cognitive structure suitable for assessment or knowledge sharing. CMs provide support to organize and represent knowledge as graphs. These graphs are networks of concepts, where nodes represent concepts and links relationships between nodes. Besides, CMs also provide a visual and holistic way to describe declarative knowledge relationships and provide an useful way for sharing information in a concise and accessible form, facilitating knowledge sharing (Novak \& Cañas, 2008).

CMs have been used worldwide to facilitate knowledge examination, construction, comparison, and reuse by users ranging from elementary graduated students to researchers. In computer science, this is no different. Although CM is considered an old education tool in other areas, in Computer Science it has shown to be a very promising research topic, since CMs provide visual representation of knowledge to support teaching and learning, mainly in Programming Languages and Software Engineering subjects (Santos, Souza, Felizardo, \& Vijaykumar, 2017). However, the study conducted by (Santos et al., 2017) reveals that although CM presents several benefits related to knowledge representation, sharing and pedagogical contribution, several problems also can be highlighted, such as cognitive overload, increased workload and scalability.

The construction of a CM requires time and effort in identifying and structuring knowledge. According to (Aguiar \& Cury, 2016a), technological advances have boosted the development of technological approaches that help the automatic construction of a CM. Although, the automatic construction of CMs from texts is still an ongoing research, especially when the map should represent a summarization of a complex text, important results can be found in the published literature. In this context, Natural Language Processing (NLP) emerges as an important instrument to construct CMs.

NLP studies how to design computer algorithms that can understand meaning and sentiment in written and spoken language and respond intelligently. It is a subset of Artificial Intelligence (AI) in the sense that AI deals with the building of systems that can do intelligent things. The goal of NLP is to get computers to perform useful tasks involving human language, tasks like enabling human-machine communication, improving human-human communication, or simply doing useful processing of text or speech (Jurafsky \& Martin, 2009). NLP techniques can be an option to extract information and build CMs.

This paper presents a systematic mapping study in order to identify the primary studies in the literature that applied NLP for automatically construct CMs. A systematic mapping study is a secondary study that provides a broad overview of an area of research to determine whether there is research evidence on a particular topic (Kitchenham \& Charters, 2007). A mapping study also helps identifying gaps in order to suggest future research and provide a direction to appropriately position new research activities in the investigated topic (Kitchenham \& Charters, 2007; Petersen, Feldt, Mujtaba, \& Mattsson, 2008). 
In general, the process for conducting secondary studies involves three main phases: Planning, Conducting and Reporting (Kitchenham, 2004). In the planning phase, a protocol for con-ducting the review is created. The protocol specifies the procedures to be followed to conduct a secondary study, such as research questions, search bases, selection criteria (inclusion and exclusion) and quality criteria of the selected studies. During the conduction phase the studies are identified and selected through the application of selection criteria. In a secondary study it is necessary to select a set of studies, called primary studies, and to select the studies considered candidates, it is necessary to use a set of selection criteria. After the selection activity, the data contained in the included studies should be extracted and synthesized. Finally, in the last phase, the results of the answers to the research questions should be published to potential stakeholders.

The mapping study presented in this paper investigates the following issues: (i) distribution of the selected studies over the years; (ii) purpose of CMs construction; (iii) automation approaches that have been used in CMs construction; (iv) NLP techniques that have been used to construct CMs; (v) NLP tools that have been used to construct CMs; (vi) NLP algorithms that have been used to construct CMs; and (vii) research type. From the mapping results, a classification scheme was designed in order to present how NLP combined with others could be used for the construction of CMs. From this classification scheme, a graph was elaborated to present different paths to construct CMs using NLP. The classification scheme and graph created can guide a new researcher in this area, for instance, better understand how the techniques can be used together for automatic creation of CMs.

This paper is organized as follows. Section 2 presents a background of this study. Section 3 presents the related work. Section 4 describes the main parts of the mapping protocol used. Section 5 discusses the selection process, the classification schemas, and presents data synthesis. Section 6 describes the designed classification scheme. Section 7 discusses the findings and the mapping limitations. Finally, Section 8 presents conclusions and future directions for this research.

\section{Background}

CMs were developed in 1972, within the research program conducted by Professor Joseph Donald Novak, at Cornell University (Novak \& Cañas, 2008). According to Novak and Cañas (Novak \&Cañas, 2008), CMs are graphic tools for representing and organizing knowledge, since the cognitive structure of an individual can be interpreted as a set of concepts related to each other.

The cognitive structure of a CM are networks of concepts, where ellipses or rectangles rep-resent concepts and links relationships between concepts. Concept can be defined as a perceived regularity in events or objects, or records of events or objects, designated by a label. The label for most of the concepts are words or symbols. Links contain associated words that describe the relationship nature between concepts. The concepts can be hierarchically organized, where more generic concepts are at their highest levels at the root, while more specific concepts appear at lower levels, elongating to the leaves, similar to a tree like structure. Figure 1 shows an example of a CM that describes the structure of CMs and illustrates the above characteristics.

CMs have been applied in pedagogical context in all disciplines including politics, philosophy of science, physics, chemistry, medicine, electrical engineering and mathematics (Katagall, Dadde, Goudar, \& Rao, 2015; Rueda, Arruarte, Elorriaga, \& Herran, 2009). In Software Engineer-ing, for instance, CMs have been applied with the purpose of assisting in different activities that involve software development process (Gurupur, Sakoglu, Jain, \& Tanik, 2014; Williams, Moore, Johri, Pierce, \& North, 2012; Faily, Lyle, Paul, Atzeni, \& Blomme, 2012; Coffey, Reichherzer, Owsnick-Klewe, \& Wilde, 2012), as well as how to organize concepts in software requirements specification (Faily et al., 2012; Coffey et al., 2012; Kof, Gacitua, Rouncefield, \& Sawyer, 2007), 
since CMs have been considered a successful tool to elicit, assimilate and share knowledge (Santos et al., 2017).

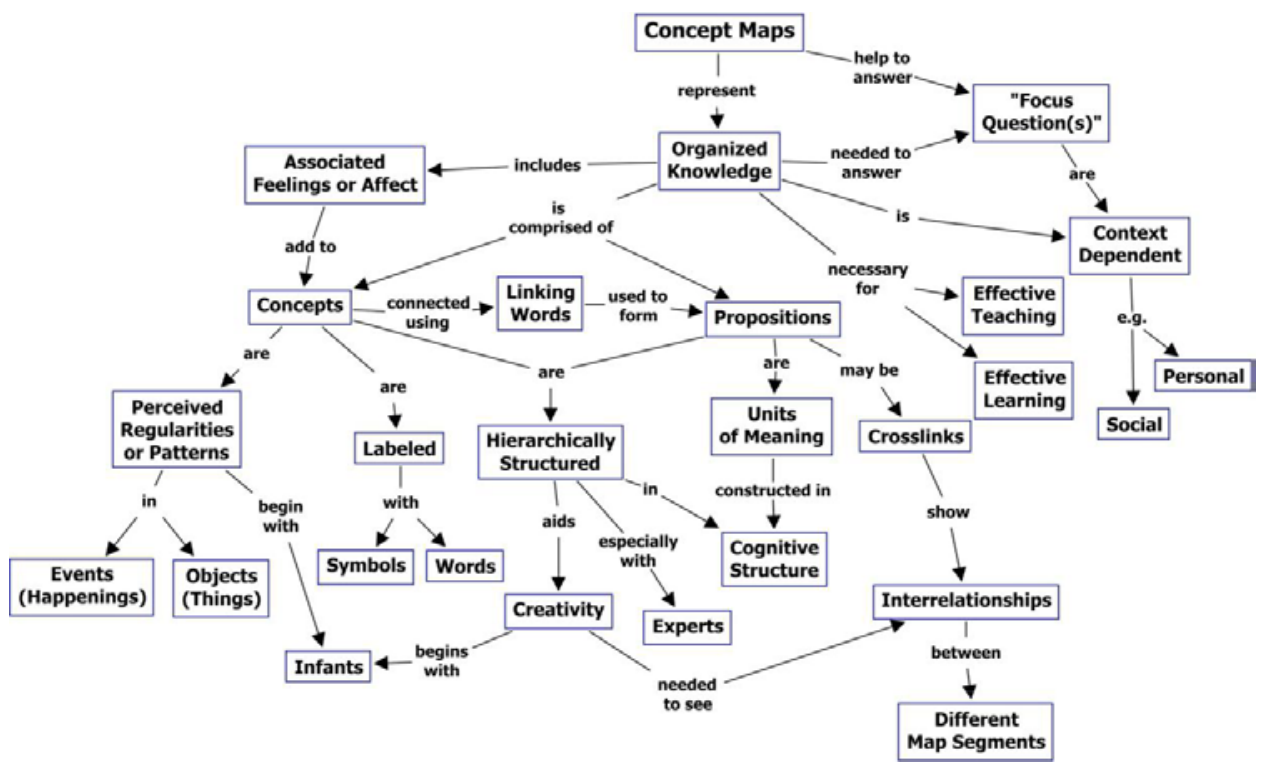

Figure 1- Example of CM showing the key features of CMs (Novak \& Cañas, 2006).

The standard procedure for building a CM involves defining (Novak \& Cañas, 2008): (i) identification of a domain of knowledge; (ii) identification and a list of the key concepts that apply to this domain; (iii) ordering of the concepts relevant from top to bottom in the map; (iv) adding and labeling the linking phrase concepts in order to construct a preliminary CM; and (v) the necessity of a revision of the map after a preliminary version is constructed. Other concepts can be added. However, the construction of a CM requires time and effort in identifying and structuring knowledge in unstructured text, especially when the domain is more complex. According to (Aguiar \& Cury, 2016a), technological advances have boosted the development of some approaches that aid in the automatic construction of a CM. Natural Language Processing (NLP) is pointed out as an important instrument to construct CMs (Qasim, Jeong, Heu, \& Lee, 2013).

NLP aims to extract a fuller meaning representation from unstructured databases, that is, language expressed in text format. From NLP, it is possible to capture meaning from an input of words (sentences, paragraphs, pages) in the form of a structured output (Cambria \& White, 2014). NLP uses linguistic concepts such as part-of-speech (i.e.: noun, verb, adjective) and grammatical structure. It has to deal with anaphora (reference to previous ideas in the text for its meaning) and ambiguities. In order to achieve this, it uses several knowledge representations, such as a lexicon of words and their meanings and grammatical properties and a set of grammar rules and several other resources (Kao \& Poteet, 2007). In this work, we intend to mapping all this resources presented in the literature to create CMs automatically.

The mechanism of NLP involves two processes: Natural Language Understanding (NLU) and Natural Language Generation (NLG).

NLU is the process of understanding the meaning of given text. Both, the nature and structure of each word of a text must be understood for NLU. In order to understand structure, NLU should resolve several types of ambiguities present in natural language: lexical as words have multiple meanings, syntactic because a sentence can have multiple parse trees, semantic as sentences can 
have multiple meanings, and anaphoric ambiguity, as certain phrases or words previously mentioned can have a different meaning. Besides ambiguity, there are certain different words having similar meaning (synonyms) and words having more than one meaning (polysemy).

NLG is the process of automatically producing text from structured data in a readable format with meaningful phrases and sentences. NLG is divided into three proposed stages: Text Planning which is responsible for ordering the content in structured data; Sentence Planning where sentences are combined from structured data to represent the flow of information; and finally Realization in which grammatically correct sentences are produced to represent text.

Although NLP and Text Mining are both interested in processing and extracting information from texts, NLP uses different levels of linguistic analysis responsible for understanding meaning and structure of a given text. Text Mining extracts hidden information inside text data through pattern recognition. NLP techniques enable extracting information and build CMs. In this work, we intent to map all these resources presented in the literature to automatically create CMs.

\section{Related Work}

In general, secondary studies are based on analyzing research papers (referred to as primary studies). Mapping studies provide an overview of a topic area and identify whether there are subtopics where more primary studies are needed (Petersen et al., 2008). The methodology used in secondary studies is intended to ensure that the literature review is unbiased, rigorous and auditable. Our approach follows this idea by performing a mapping study.

Before accomplishing the secondary study presented in this paper, we performed a tertiary study looking for secondary studies investigating CMs in the same topic. Tertiary studies are considered as a review that focuses only on secondary studies, i.e., it is a review about other secondary studies (Kitchenham \& Charters, 2007). In this tertiary study, we used the search string shown in Table 1.

Table 1: Keywords of the Search String of the Tertiary Study on CMs and NLP.

\begin{tabular}{|c|c|}
\hline Areas & Keywords \\
\hline Concept Map & $\begin{array}{l}\text { “Concept Map”, “Concept Maps”, “Conceptual Map”, “Conceptual } \\
\text { Maps”, “Concept Mapping” }\end{array}$ \\
\hline $\begin{array}{l}\text { Natural Language } \\
\text { Processing }\end{array}$ & $\begin{array}{l}\text { “text data mining”, “text mining”, “text analysis”, “automatic”, } \\
\text { "automatically”, “text processing”, “natural language processing”, } \\
\text { "NLP” }\end{array}$ \\
\hline Secondary Study & $\begin{array}{l}\text { "Systematic Literature Review”, "Systematic Review”, "Systematic } \\
\text { Mapping”, “Mapping Study”, "Mapping Studies”, "Systematic } \\
\text { Literature Mapping” }\end{array}$ \\
\hline Search String: & $\begin{array}{l}\text { (“Concept Map” OR “Concept Maps” OR “Conceptual Map” OR } \\
\text { "Conceptual Maps” OR “Concept Mapping”) AND (“text data } \\
\text { mining” OR “text mining” OR “text analysis” OR “automatic” OR } \\
\text { “automatically” OR “text processing” OR “natural language } \\
\text { processing” OR “NLP”) AND (“Systematic Literature Review” } \\
\text { OR “Systematic Review” OR “Systematic Mapping” OR “Mapping } \\
\text { Study” OR “Mapping Studies” OR “Systematic Literature } \\
\text { Mapping”) }\end{array}$ \\
\hline
\end{tabular}


In this step, only an automatic search was conducted, i.e., we executed the search string directly in the electronic databases. The search string presented in Table 1 was applied in the following electronic databases: IEEE Xplore, ACM Digital Library, Scopus, Science Direct and Compendex. 75 results were returned. After eliminating duplications and applying the same selection criteria presented in section 4.2, 19 secondary studies were returned. In all the returned studies we attempted to identify whether the study referred, in fact, to CMs and NLP. However, we did not find any secondary study that addressed CMs and NLP. Thus, we conducted a manual search in order to identify traditional review that addressed the same scope of this research. Two studies attracted our attention.

In Kowata et al. (Kowata, Cury, \& Boeres, 2010b), a review of semi-automatic approaches to construct CMs was conducted.This review defined a set of classifications which were organized according to some perspectives, such as research goals, data sources and outputs. More recently, in Aguiar and Cury (Aguiar \& Cury, 2016b), a categorization based on bibliographic review of the area between 1994 and 2015 was developed. This study considered the same perspectives presented in Kowata et al. (Kowata et al., 2010b), but with more categories, such as, idiom, domain, analysis and size.

In a similar way to Kowata et al. (Kowata et al., 2010b) and Aguiar and Cury (Aguiar \& Cury, 2016b), we also investigated similar perspectives in the included studies. Our perspectives were defined from classifications identified based on our research questions. However, with respect to data sources perspective, our focus was on tools and algorithms used to construct CMs considering NLP techniques. In addition, unlike the related published literature, we conducted a secondary study.

The following sections present the systematic mapping that we conducted in our study.

\section{Research Protocol}

The research method for this mapping study was defined based on the guidelines given in Kitchenham and Charters (Kitchenham \& Charters, 2007). It involves three main phases: (i) Planning: refers to the pre-review activities, and it establishes a review protocol defining the research questions, inclusion and exclusion criteria, sources of studies, search string, and mapping procedures; (ii) Conducting: focuses on searching and selecting the studies, in order to extract and synthesize data from included ones; (iii) Reporting: is the final phase and it writes up the results and circulates them to potentially interested parties. Following are the main parts of the mapping protocol used in this work.

\subsection{Research questions}

This mapping study aims at answering the following Research Questions (RQ) presented in Table 2: 
Table 2: Research questions and their rationales

\begin{tabular}{|c|c|c|}
\hline $\mathbf{N}^{\mathbf{0}}$ & Research Question & $\begin{array}{l}\text { Rationale } \\
\end{array}$ \\
\hline RQ1 & $\begin{array}{l}\text { When and Where } \\
\text { have } \\
\text { The studies been } \\
\text { published? }\end{array}$ & $\begin{array}{l}\text { The topic of this mapping study seems to be broad and new. This } \\
\text { research question aims at giving an understanding on whether } \\
\text { there are specific publication sources for these studies, and when } \\
\text { they have been published. }\end{array}$ \\
\hline RQ2 & $\begin{array}{l}\text { What are the } \\
\text { purposes } \\
\text { of constructing } \\
\text { CMs } \\
\text { based in NLP? }\end{array}$ & $\begin{array}{l}\text { Investigates what are the purposes for constructing CMs. This } \\
\text { information can help to identify which aspects of CMs have } \\
\text { gained more attention when applying NLP. }\end{array}$ \\
\hline RQ3 & $\begin{array}{l}\text { What is the } \\
\text { automation level } \\
\text { that has been used } \\
\text { in the CM } \\
\text { construction based } \\
\text { in NLP? }\end{array}$ & $\begin{array}{l}\text { Different construction level have been presented in scientific } \\
\text { papers (e.g., automatic or semiautomatic). This research question } \\
\text { investigates which automation level is reported in each selected } \\
\text { study. This is important to identify the scalability of techniques } \\
\text { used. An automated technique often presents an improved } \\
\text { scalability than a semiautomatic technique, since there is no } \\
\text { manual intervention. }\end{array}$ \\
\hline RQ4 & $\begin{array}{l}\text { What } \\
\text { techniques } \\
\text { have been used to } \\
\text { construct CMs? }\end{array}$ & $\begin{array}{l}\text { Highlights the main techniques used to provide the CM } \\
\text { constructions. This is useful for researchers and practitioners that } \\
\text { intend to construct CM based on NLP. }\end{array}$ \\
\hline RQ5 & $\begin{array}{l}\text { What NLP tools } \\
\text { have been used to } \\
\text { construct CMs? }\end{array}$ & $\begin{array}{l}\text { Highlights the main tools used to provide the CM constructions. } \\
\text { This is useful for researchers and practitioners that intend to } \\
\text { construct CM based on NLP, as well as to guide future research } \\
\text { towards new technologies in order to fill the existing gaps. }\end{array}$ \\
\hline RQ6 & $\begin{array}{l}\text { What NLP } \\
\text { algorithms } \\
\text { Have been used to } \\
\text { construct CMs? }\end{array}$ & $\begin{array}{l}\text { Highlights the main algorithms used to provide the CMs } \\
\text { construction. This is useful for researchers and practitioners that } \\
\text { intend to construct CM based on NLP, as well as to guide future } \\
\text { research towards new technologies in order to fill the existing } \\
\text { gaps. }\end{array}$ \\
\hline RQ7 & $\begin{array}{l}\text { What types of } \\
\text { research have been } \\
\text { done? }\end{array}$ & $\begin{array}{l}\text { This research question investigates which research type is reported } \\
\text { in each selected study. This is an important question, since it can } \\
\text { be used to evaluate the current maturity stage of the area. As } \\
\text { pointed out by Petersen et al. (2008) and Wieringa et. al (2005), } \\
\text { different types of research have been presented in scientific papers } \\
\text { (e.g., solution proposal, validation research, experience papers, } \\
\text { opinion paper and evaluation research). }\end{array}$ \\
\hline
\end{tabular}

\subsection{Inclusion and Exclusion Criteria}

The selection criteria are organized in one inclusion criterion (IC) and six exclusion criteria (EC).

The inclusion criterion is: 
(IC1) The study must present an approach of CM construction using NLP.

The exclusion criteria are:

(EC1) The study is published as a short paper or extended abstract;

(EC2) The study is not written in English;

(EC3) The study is an older version (less updated) of another study already considered;

(EC4) The study is not a primary study, such as editorials, summaries of keynotes, workshops, and tutorials;

(EC5) The full paper is not available;

(EC6) The study presents a CM construction approach, but it does not use NLP;

The search for primary studies was conducted using manual search and automatic search, both will be described in the sections 4.3 and 4.4 .

\subsection{Manual review}

In order to identify the main keywords to construct the search string of our systematic review (mapping study), we conducted a manual review. The selection process used in this manual review was based on (Molleri, Petersen, \& Mendes, 2016). In this manual research we decided to analyze all volumes of the proceedings of International Conference on Concept Mapping (CMC) until 2016 (presented in Table 3). CMC proceedings contain initiatives in multiple areas focusing on new ways to construct and use CMs.

The candidate studies were analyzed considering, first, reading title, abstract and keywords. Afterwards the studies were analyzed considering the entire text.

For the studies selection the same inclusion and exclusion criteria defined in Section 4.2 were used in both selection stages. After studies selection, collection and analysis, the back-ward snowballing technique was applied seeking to identify other studies relevant to the mapping. Snowballing is a process that checks if selected studies cite other relevant studies, retrieves those studies, and continue this process until no more relevant studies are found (Jalali \& Wohlin, 2012).

Table 3: Proceedings used in Manual Review.

\begin{tabular}{c|c|l}
\hline Year & Volume & \multicolumn{1}{c}{ Theme } \\
\hline 2004 & 1 & Concept Maps: Theory, Methodology, Technology \\
\hline 2006 & 2 & Concept Maps: Theory, Methodology, Technology \\
\hline 2008 & 3 & Concept Maps: Connecting Educators \\
\hline 2010 & 4 & Concept Maps: Making Learning Meaningful \\
\hline 2012 & 5 & Concept Maps: Theory, Methodology, Technology \\
\hline 2014 & 6 & Concept Mapping to Learn and Innovate \\
\hline 2016 & 7 & Innovating with Concept Mapping \\
\hline
\end{tabular}




\subsection{Automatic review}

After conducting the manual review, the main keywords to be used in the automatic review for the mapping study were defined. The details for the mapping study are detailed below.

(I) Keywords and Search String

The search string considered two areas, CMs and NLP (Table 4), and it was applied in three metadata fields (title, abstract and keywords). The search string was modified to be adapted to particularities of each source.

Table 4: Keywords search.

\begin{tabular}{c|l}
\hline Areas & \multicolumn{1}{c}{ Keywords } \\
\hline Concept Map & $\begin{array}{l}\text { “concept map”, “concept maps”, “conceptual map”, “concept map } \\
\text { mining”, “conceptual maps”, “concept mapping”. }\end{array}$ \\
\hline $\begin{array}{c}\text { Natural } \\
\text { Panguage }\end{array}$ & $\begin{array}{l}\text { "text data mining”, “text mining”, “text analysis”, “automatic”, } \\
\text { "automatically”, “text processing”, “natural language processing”, } \\
\text { "NLP”. }\end{array}$ \\
\hline $\begin{array}{l}\text { (“concept map” OR “concept maps” OR “conceptual map” OR } \\
\text { "concept map mining” OR “conceptual maps” OR “concept } \\
\text { mapping”) } \\
\text { AND (“text data mining” OR “text mining” OR “text analysis” OR } \\
\text { "automatic” OR “automatically” OR “text processing” OR “natural } \\
\text { language processing” OR “NLP”) }\end{array}$ \\
\hline
\end{tabular}

(II) Sources

The sources used were:

- IEEE Xplore (http://ieeexplore.ieee.org)

- ACM Digital Library (http://dl.acm.org)

- Scopus (http://www.scopus.com)

- Science Direct (http://www.sciencedirect.com)

(III) Data storage

The studies returned in the searching phase were cataloged and stored appropriately. This catalog helped us in the classification and analysis procedures.

(IV) Assessment

Before conducting the mapping study, we tested the mapping protocol. This test was con-ducted in order to verify its feasibility and adequacy, based on a pre-selected set of studies considered relevant to our investigation. Firstly, the review process was conducted by the first author of this paper, in a second moment, three area specialists carried out the review validation. The specialists analyzed $30 \%$ of the studies using three different samples. 


\section{Conducting the mapping study}

In this section, we discuss the main stages taken to conduct systematic mapping. This process is illustrated in Figure 2.

\subsection{Manual review}

From manual review 52 studies were considered candidates to be analyzed. In the first analysis stage, the selection criteria (inclusion and exclusion criteria) were applied for title, abstract and keywords, resulting in 20 studies. Then, we applied the selection criteria in the full text leading to include 6 studies. Over these 6 studies, we complemented the manual search by means of backward snowballing. The process was performed in three iterations, as a number of relevant references was still available after the first iteration. After applying the selection criteria, only 1 study remained at the end of this process. Thus, we selected 7 studies to compose the final set; 6 from CMC proceedings and 1 from snowballing. From the set of studies collected in the manual review we identified the main keywords to compose the search string used in the automatic review.

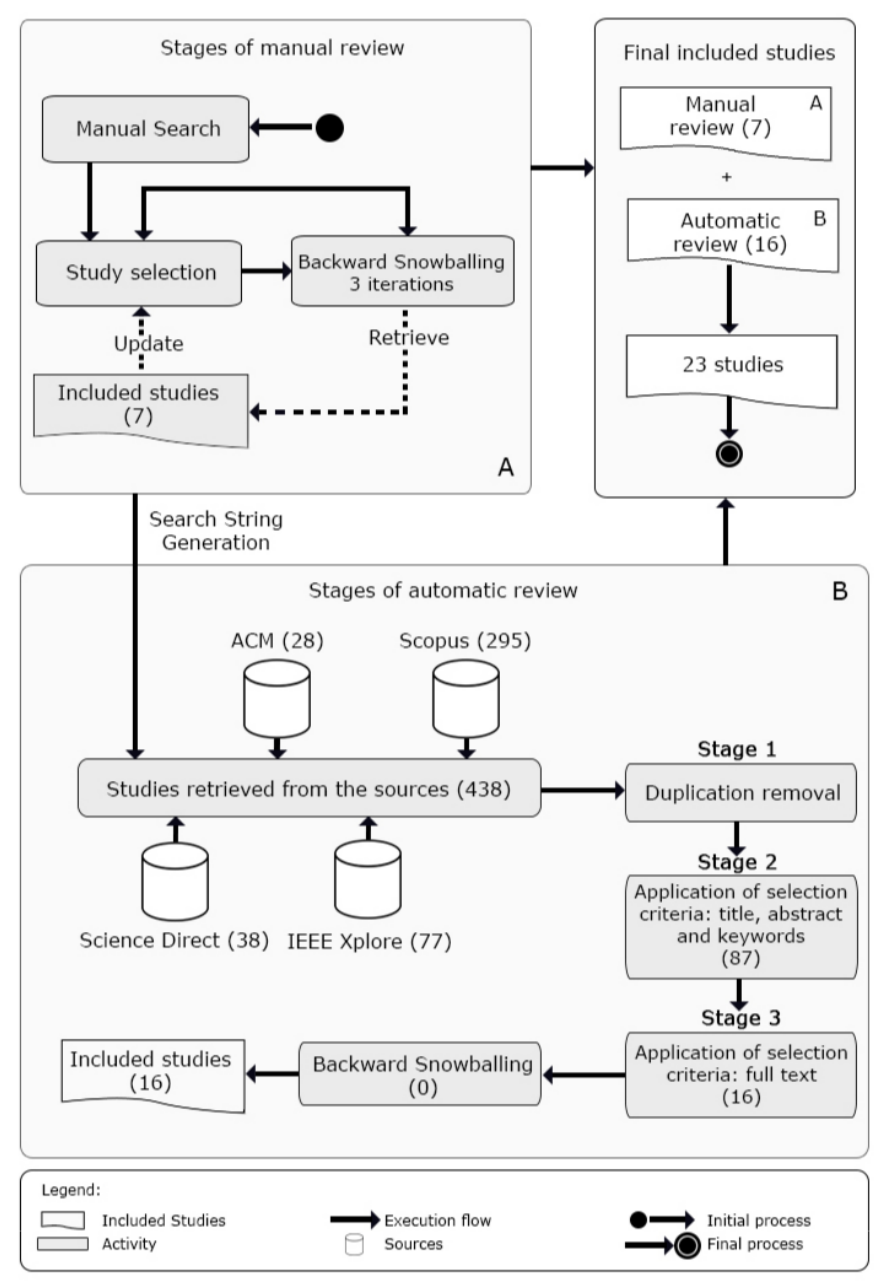

Figure 2: Search and selection process. 


\subsection{Automatic review}

In the automatic review process we considered the studies published until December 2016. As a result, a total of 438 publications were returned, out of which 77 from IEEE Xplore, 295 from Scopus, 38 from Science Direct, and 28 from ACM Digital Library.

The selection process in the automatic review was divided into 3 stages. The first stage eliminated duplicates reducing to 306 (approximately 29,5\% reduction), since many publications.

From the third stage of the selection process, 16 studies were considered relevant, from which data were extracted. 16 out of 438 was the final number in the systematic review, with a reduction rate of about $96.3 \%$. As a final result, we got to 23 studies to be analyzed ( 7 from manual review and 16 from automatic review). The 23 final articles references are presented in Table 5.

Table 5: List of IDs and references.

\begin{tabular}{|c|l|r|l|}
\hline ID & \multicolumn{1}{|c|}{ Citation } & ID & \multicolumn{1}{|c|}{ Citation } \\
\hline 1 & (Aguiar \& Cury, 2016a) & 13 & (Olney, Cade, \& Williams, 2011) \\
\hline & (Bui, Del Fiol, Hurdle, \& Jonnalagadda, & & \\
& $2016)$ & 14 & (Qasim et al., 2013) \\
\hline 3 & (Caputo \& Ebecken, 2011) & 15 & (Richardson \& Fox, 2005) \\
\hline 4 & (Ceausu \& Després, 2007) & 16 & (Valerio, Leake, \& Cañas, 2012) \\
\hline 5 & (Atapattu, Falkner, \& Falkner, 2015) & 17 & (Villalon \& Calvo, 2011) \\
\hline 6 & (Silva, Morais, \& Monteiro, 2014) & 18 & (Wang, Cheung, Lee, \& Kwok, 2008) \\
\hline & (Junqueira, Silva, Patrícia, \& Maximiano, & & \\
\hline 7 & 2014) & 19 & (Wang, Cheung, Lee, \& Kwok, 2009) \\
\hline 8 & (Ke, 2013) & 20 & (Yang, 2015) \\
\hline 9 & (Kowata, Cury, \& Boeres, 2010a) & 21 & (Yoon, Lee, \& Lee, 2014) \\
\hline & (Martin-Rodilla \& Gonzalez-Perez, & & \\
\hline 10 & 2016) & 22 & (Zouaq \& Nkambou, 2008) \\
\hline & (Nugumanova, Mansurova, Alimzhanov, & & (Zouaq, Nkambou, Frasson, Wilson, \& \\
11 & Zyryanov, \& Apayev, 2015) & 23 & Sutcliffe, 2007) \\
\hline 12 & (A. Oliveira, Pereira, \& Cardoso, 2001) & & \\
\hline
\end{tabular}

\subsection{Data Extraction and classification}

In order to answer the research questions from the 23 selected studies, we used a form containing the following parameters: bibliographic reference, purpose, automation level, techniques, tools and algorithms used to construct CMs. This form was used to extract the answers. Therefore, before the extraction, categories for classifying the studies were defined according to the research questions. So, depending on the focus of each category item, the study was classified as one or any of its combination. In addition, we used as base the categories defined in the two related studies returned in the tertiary mapping presented in Section 3 (Kowata et al., 2010a; Aguiar \& Cury, 2016b). Categories were defined as follows.

Classification schema for purposes (RQ2): in this classification, we wanted to know the reasons to automatically construct CMs. We have identified two main categories of such purposes: educational and analytical. Educational: CMs are used as tools to improve the teaching and learning process. Analytical: CMs are used to explore, analyze and discover patterns in specific databases. 
Classification schema for automation level (RQ3): two categories were used to classify the automation level to construct CMs: automatic and semiautomatic. Automatic: is an approach where inputs are provided (in natural language) and the CM is automatically constructed without any human interference. Semiautomatic: is quite similar to the automatic category, however it may suffer human interference in the construction of CMs.

Classification schema for techniques used (RQ4): when analyzing a text computationally it is necessary to choose which characteristics of the text will be analyzed (e.g.: quantity of words that repeat, structure grammar, syntax or morphology). Depending on the characteristic chosen for analysis, the technique used to extract the information is different. NLP techniques can be classified into the following three main categories: linguistic, statistical and hybrid.

Linguistic: uses morphology, grammar, syntax, semantics and other linguistic resources to deal with text. The methods used are directly linked to text structure based on linguistics and pattern recognition. Statistical: in this category it is very common to analyze the frequency of terms and the co-occurrence of terms in the document. One of the advantages of using this category is simplicity, as it does not consider linguistics. However, there are also disadvantages, such as the loss of relevant information regarding the semantic approach. Hybrid: are studies that use a combination of linguistic and statistical techniques, based on syntactic parsing, linguistic filters and statistical measures.

Classification schema for tools used (RQ5): this classification discusses the tools that have been used or proposed to support the process of building CMs from natural language. We considered as tool, any previously implemented software that would aid in any stage of the construction of CMs, that is, in the extraction of concepts, relationships or even the summarization and data display.

Classification schema for algorithms used (RQ6): In this research question the classification "algorithms" grouped the algorithms used to perform the extraction of the concepts, relation-ships and assist in the summarization of CMs.

What is the research type (RQ7): in this research question we adopted an existing classification: the one proposed by (Wieringa, Maiden, Mead, \& Rolland, 2005), and revisited by (Petersen et al., 2008). Based on the selected studies, we disregarded some of its categories, since none of the selected studies was classified in those categories. The categories used in this mapping are summarized below. As pointed out by (Wieringa et al., 2005), studies can span more than one category, although some combinations are unlikely.

Solution proposal: in this research approach, the study proposes a solution for a problem and argues for its relevance, without a full-blown validation. The solution must be novel, or at least a significant improvement of an existing one. A proof-of-concept may be offered by means of a small example, a sound argument, or by some other means.

Validation research: in this research approach, the study investigates the properties of a proposed solution that has not yet been implemented in practice. It may have already been proposed elsewhere by the author or by someone else. The investigation uses a thorough, methodologically sound research setup. Possible research methods include, among others, experiments, prototyping and simulation.

Evaluation research: in this type of research, the study discusses the implementation of a technique in practice, and what are the consequences of the implementation in terms of benefits and drawbacks (implementation evaluation). The novelty of the technique is not necessarily a contribution of the study. However, if no industry cooperation or real world project is mentioned, then the study cannot be considered an evaluation research (Petersen et al., 2008). 


\subsection{Synthesis and data analysis}

In order to offer a general view of efforts in the area of constructing CMs using NLP, a distribution of the 23 selected papers over the years is shown in Figure 3 (RQ1). As this Figure suggests, the use of NLP to build CMs is recent, occurring basically from 2001 to nowadays, showing a slight increase in the number of publications in 2011 and from 2014 to 2016.

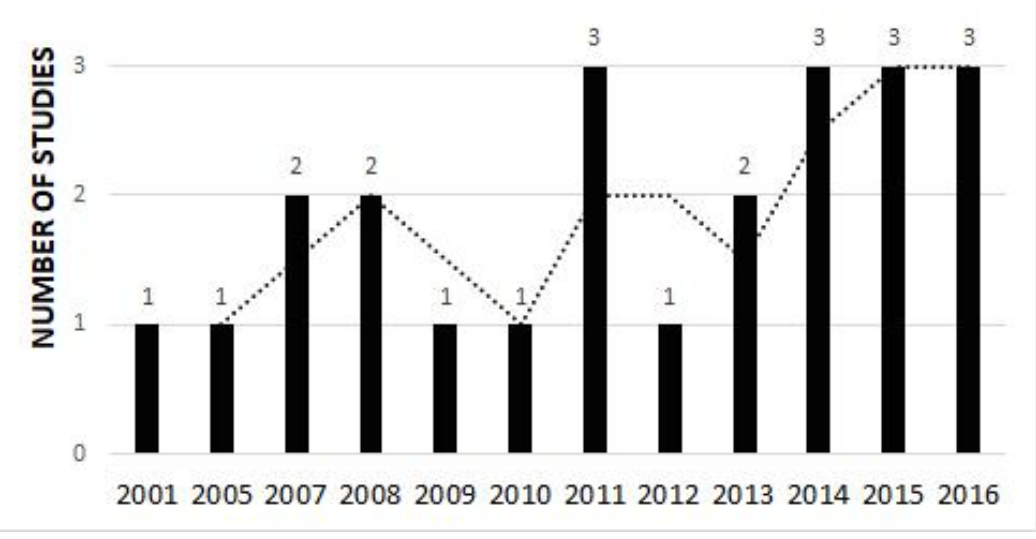

Figure 3: Distribution of the selected studies over the years.

Table 6: Publication Sources.

\begin{tabular}{|l|l|l|}
\hline ID & Type & Publication sources \\
\hline 1 & Conference & International Conference on Concept Mapping \\
\hline 2 & Journal & Journal of Biomedical Informatics \\
\hline 3 & Congress & World Congress on Nature and Biologically Inspired Computing \\
\hline 4 & Workshop & CEUR Workshop \\
\hline 5 & Conference & International Conference on Artificial Intelligence in Education \\
\hline 6 & Conference & International Conference on Intelligent Systems Design and Applications \\
\hline 7 & Conference & International Conference in Concept Mapping \\
\hline 8 & Journal & Information Technology Journal \\
\hline 9 & Conference & International Conference on Concept Mapping \\
\hline 10 & Conference & World Congress on Nature and Biologically Inspired Computing \\
\hline 11 & Conference & International Conference on Data Management Technologies and Applications \\
\hline 12 & Symposium & International Symposium on Artificial Intelligence \\
\hline 13 & Conference & Workshop on Innovative Use of NLP for Building Educational Applications \\
\hline 14 & Journal & Journal of Information Science \\
\hline 15 & Conference & Joint Conference on Digital Libraries \\
\hline 16 & Conference & International Conference on Concept Mapping \\
\hline 17 & Journal & Educational Technology and Society \\
\hline 18 & Journal & Information Processing and Management \\
\hline 19 & Journal & Expert Systems with Applications \\
\hline 20 & Journal & Educational Technology \& Society \\
\hline & & International Conference on Industrial Engineering and Other Applications of \\
\hline 21 & Conference & Applied Intelligent Systems \\
\hline 22 & Journal & American association for Artificial intelligence \\
\hline 23 & Conference & FLAIRS Conference \\
\hline & & \\
\hline
\end{tabular}


The purpose of creating CMs in the selected studies is analyzed in RQ2. As shown in Figure 4, educational purpose has the largest representativeness in the analyzed approaches. Studies classified as educational (14 studies - 60.8\%) showed an interest in using the knowledge extracted from texts to improve the teaching of a given domain. For example, in (Yang, 2015), the effects of automatic scaffolding and measurement of three-layer CMs on improving university students' writing summaries were investigated. On the other hand, studies classified as analytical (9 studies - 39.3\%) have used CMs as tools to understand a particular research area. In (Caputo \& Ebecken, 2011), for instance, the authors interpret the information available in documents that describe products and create a mechanism to accelerate the information interpretation.

RQ3 analyzes the automation level in creating CMs. Automation level can be of two types: automatic and semi-automatic. In the 23 selected studies, both are considered. As Figure 5 shows,

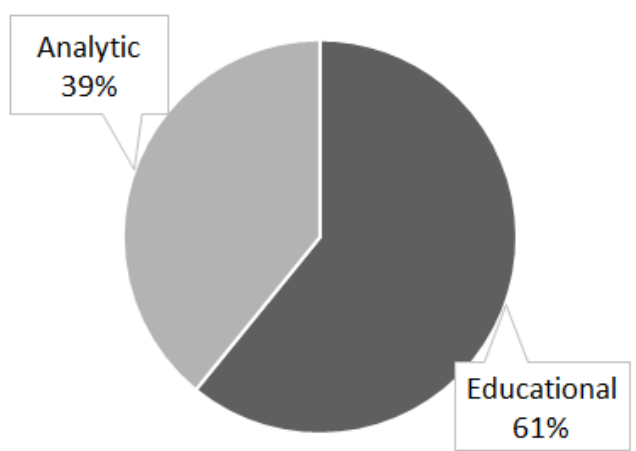

Figure 4: Distribution per purposes reported.

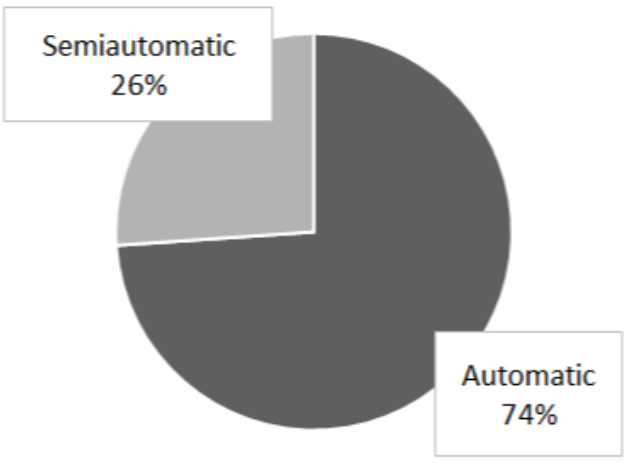

Figure 5: Distribution per automatization level.

most studies use the automatic extraction of terms and relationships (17 studies - 73.9\%). Qasim and Jeong (Qasim et al., 2013), for example, proposed an algorithm for automatic candidate term extraction from text documents to construct a CM. Techniques as anaphoric resolution (for pronouns to increase recall by finding more propositions in text documents) clustering, information retrieval and structural similarity measuring, were applied to achieve high performance. On the other hand, studies classified as semi-automatic represent $26.8 \%$ (6 studies). This automation level has some human intervention in constructing CMs. In (A. Oliveira et al., 2001), the authors proposed the construction of CMs from NLP and Machine Learning. However, at some point in the construction, the developed system interacts with the users by asking questions for validating CMs concepts or relationships and improves the software performance.

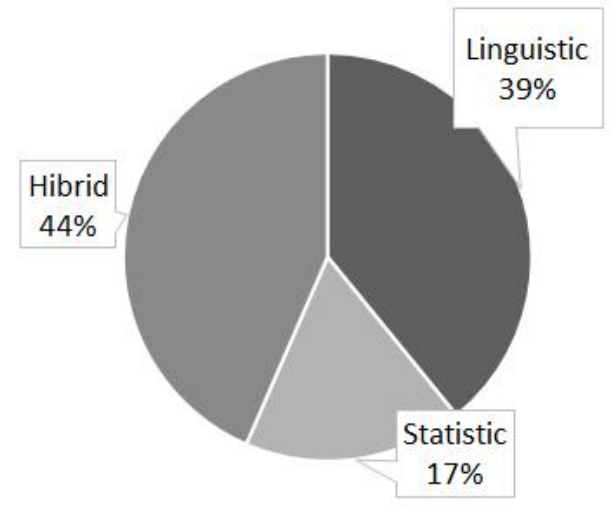

Figure 6: Distribution per NLP techniques.

From RQ4 we mapped the type of NLP techniques used in the selected studies. As mentioned in Section 5.3, the techniques could be classified into linguistic, statistical and hybrid. Figure 6 
shows the distribution of the studies according to these categories. Statistical technique was identified in $17.3 \%$ (4 studies) of the selected studies. These studies are based on classical algorithms such as the Term Frequency (Caputo \& Ebecken, 2011; Nugumanova et al., 2015; Yang, 2015). Another widely used technique is linguistics (9 studies - 39.1\%). This is characterized by the use of grammar and linguistic rules for extracting concepts and relationships. Some studies uses the classification of words according to their function in a sentence (Wang et al., 2009; Yang, 2015; Zouaq \& Nkambou, 2008). Another example of linguistic technique applied in the studies is the extraction of relationships by mapping the subject, verbs and objects to determine the existence of a relation (Atapattu et al., 2015). Finally, the so-called hybrid technique (10 studies 43.5\%) combines statistical algorithms and linguistics in CM construction. The concepts collection through the terms frequency can be combined with techniques that locate the function of each word in a sentence, resulting in a richer approach, as presented in (Wang et al., 2008).

In order to summarize the results found for RQ2, RQ3 and RQ4, we have also added the results in the table format (Table 7). Thus, it is possible to see exactly which studies are classified in each categories created for the respective RQs. Table 7 can support researchers to select studies with specific characteristics.

Table 7: Classifications and studies found by RQ2, RQ3 and RQ5

\begin{tabular}{|c|c|c|c|c|c|c|c|}
\hline ID & Educational & Analytic & Automatic & Semiautomatic & Linguistic & Statistical & Hybrid \\
\hline 1 & & $\checkmark$ & $\checkmark$ & & $\checkmark$ & & \\
\hline 2 & $\checkmark$ & & & $\checkmark$ & & & $\checkmark$ \\
\hline 3 & & $\checkmark$ & $\checkmark$ & & & & $\checkmark$ \\
\hline 4 & & $\checkmark$ & $\checkmark$ & & & & $\checkmark$ \\
\hline 5 & $\checkmark$ & & $\checkmark$ & & & & $\checkmark$ \\
\hline 6 & & $\checkmark$ & $\checkmark$ & & $\checkmark$ & & \\
\hline 7 & $\checkmark$ & & $\checkmark$ & & & $\checkmark$ & \\
\hline 8 & $\checkmark$ & & $\checkmark$ & & $\checkmark$ & & \\
\hline 9 & & $\checkmark$ & $\checkmark$ & & $\checkmark$ & & \\
\hline 10 & & $\checkmark$ & & $\checkmark$ & $\checkmark$ & & \\
\hline 11 & $\checkmark$ & & $\checkmark$ & & & $\checkmark$ & \\
\hline 12 & $\checkmark$ & & & $\checkmark$ & & & $\checkmark$ \\
\hline 13 & $\checkmark$ & & $\checkmark$ & & $\checkmark$ & & \\
\hline 14 & & $\checkmark$ & $\checkmark$ & & & & $\checkmark$ \\
\hline 15 & $\checkmark$ & & & $\checkmark$ & $\checkmark$ & & \\
\hline 16 & $\checkmark$ & & $\checkmark$ & & $\checkmark$ & & \\
\hline 17 & $\checkmark$ & & $\checkmark$ & & & & $\checkmark$ \\
\hline 18 & & $\checkmark$ & $\checkmark$ & & $\checkmark$ & & \\
\hline 19 & & $\checkmark$ & $\checkmark$ & & $\checkmark$ & & \\
\hline 20 & $\checkmark$ & & $\checkmark$ & & & $\checkmark$ & \\
\hline 21 & & $\checkmark$ & $\checkmark$ & & & & $\checkmark$ \\
\hline 22 & $\checkmark$ & & $\checkmark$ & & $\checkmark$ & & \\
\hline 23 & $\checkmark$ & & & $\checkmark$ & & $\checkmark$ & \\
\hline
\end{tabular}




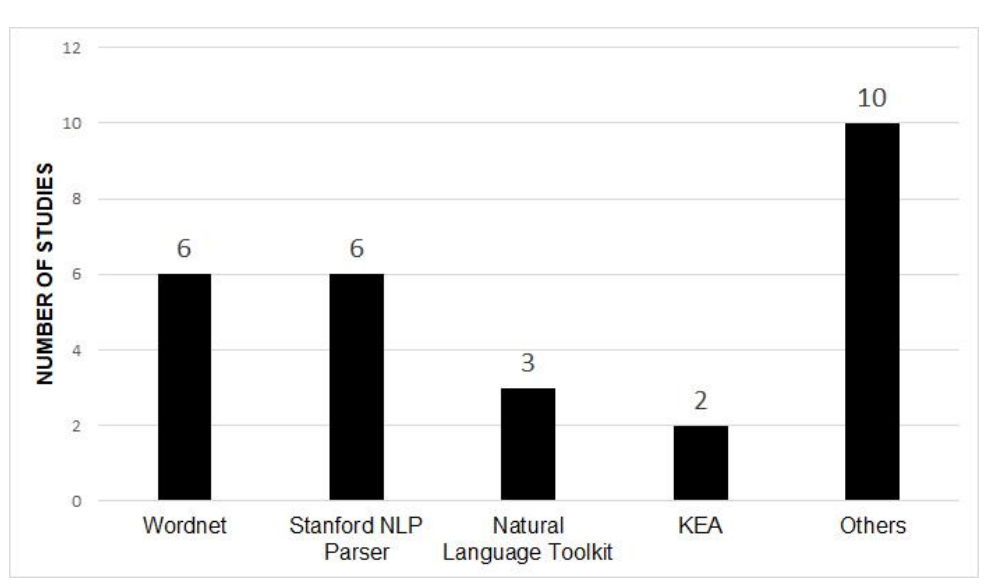

Figure 4: Distribution of tools used.

The tools (RQ5) used to construct CMs are shown in Figure 7. We found 15 different tools in this context. Wordnet tool was used in 6 studies (26.8\%), most of them applying to normalize the synonymous relations so that it is possible to deal with the large number of terms that vary according to the context (Wang et al., 2008). Another tool widely used was the Stanford NLP Parser (6 studies - 26.8\%). This tool has several modules and implements NLP techniques, including the identification of part of speech, (Zouaq \& Nkambou, 2008; Zouaq et al., 2007). Similarly, the Natural Language Toolkit (3 studies - 13.4\%) was also used to extract concepts and relationships using linguistic and statistical algorithms (Caputo \& Ebecken, 2011). Other tools were also identified in 12 articles: KEA, Tex Comom, Weka, among others.

In order to answer RQ6, we mapped the algorithms used to support creating CMs or in the extraction of concepts and relationships in a text. As shown in Figure 8, there is a huge number of algorithms used to support the creation of CMs. The most popular algorithms were used to recognize parts of speech, as the Part-Of-Speech Tagger (POS Tagger) algorithm (14 studies $60.8 \%)$ and counting the term frequency, as the Term Frequency-Inverse Document Frequency (TF-IDF) (7 studies - 30.4\%). Some linguistic algorithms, such as Subject-Verb-Object (4 studies - 17.3\%) and anaphora resolution (5 studies - 21.7\%), were also applied to extract concepts and relationships. Other algorithms were also observed in 9 other studies: Latent Semantic Analysis, Clustering, among others. The studies was classified in each category associated to RQ5 and RQ6 were summarized in Table 8.

In order to answer RQ7 question, we have analyzed the 23 studies and assigned one or more of the classes described in the 5.3 section. Considering the studies selected in this mapping, there is a great interest in implementing the proposals in practice. As Figure 9 shows, $82 \%$ of the studies present a solution proposal. Validation researches were found in $47 \%$ of the studies. Finally, evaluation researches were found in $30 \%$ of the studies. Table 9 shows the studies and what type of research they use. 


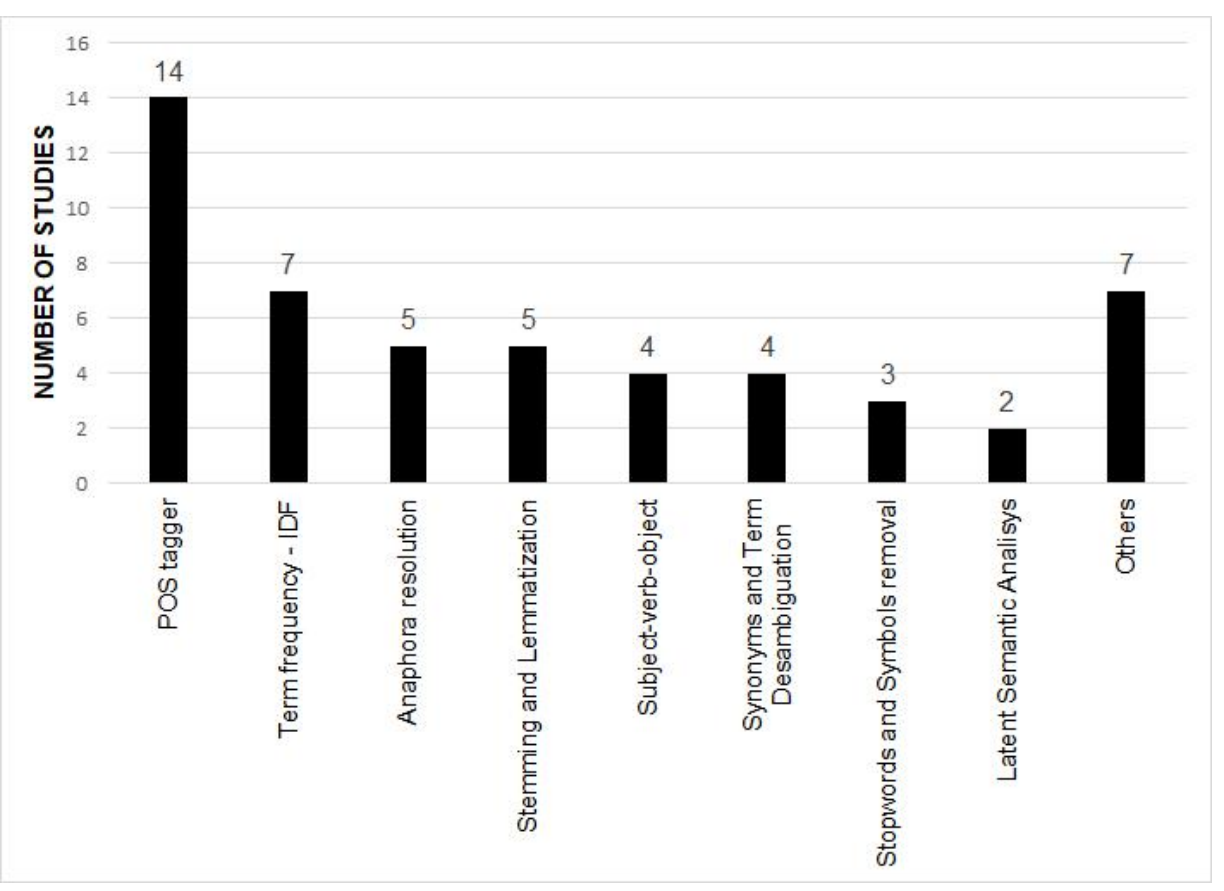

Figure 5: Distributions of algorithms

Observing Table 9, it is possible to perceive the presence of 7 studies that are classified as "Evaluation Research". In order to represent the results obtained in that studies, Table 10 shows the research area, summary of the results, number of participants and the evaluation technique used. Only 3 of the 7 studies present an evaluation Computer Science. However, in the 7 studies the usage of techniques for automatic CMs construction provided gains on the metrics evaluated (support in finding concepts and relationships (Qasim et al., 2013; Wang et al., 2008) , learning (Atapattu et al., 2015), CM construction time (Junqueira et al., 2014), study selection (Richardson \& Fox, 2005), reading (Valerio et al., 2012), comprehension (Valerio et al., 2012; Yang, 2015) and writing (Yang, 2015)). Considering the techniques used for evaluation, two techniques were found: (1) compare the CMs generated automatically with those generated by humans (4 of 7 studies). (2) the CMs are evaluated by the participants (4 of 7 studies).

\section{Classification schema for creating CMs based in NLP}

From the mapping study results, especially with respect to RQ4, RQ5 and RQ6, a classification schema was designed to present which NLP tools and algorithms have been used to support CMs elaboration. Figure 10 presents the classification schema structure. The classification schema guides new implementations associated with the construction of CMs using NLP techniques. The classification schema presents all the concepts that were addressed in the 23 articles selected in the mapping, as well as how these concepts can be distributed in four main quadrants defined according to two dimensions: linguistic and statistical NLP methods; concepts association and concepts selection tasks for building CMs.

Two quadrants of the classification schema are related to the algorithms and tools used in the 23 selected studies. The classification schema presents the division of algorithms and tools according to the purpose for which they are intended to be used, that is, considering the purpose for concepts association or for concepts selection. The concepts selection obtains from a text the words that best represent its domain. On the other hand, the associations extraction aims to detect possible connections between previously selected concepts. 
Table 8: Classifications and studies found by RQ5 and RQ6.

\begin{tabular}{|c|c|c|c|c|c|c|c|c|c|c|c|c|}
\hline$\theta$ & 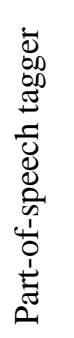 & 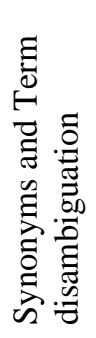 & 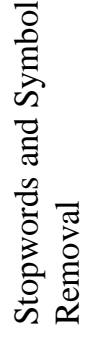 & 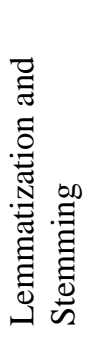 & 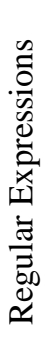 & 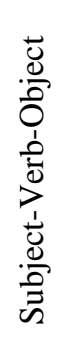 & 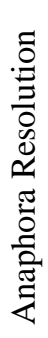 & 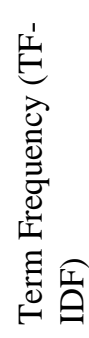 & 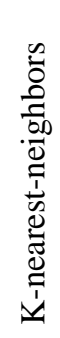 & 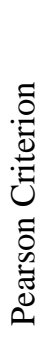 & 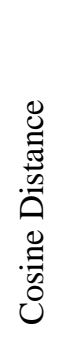 & 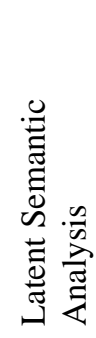 \\
\hline 1 & $\checkmark$ & & $\checkmark$ & & & & $\checkmark$ & & & & & \\
\hline 2 & $\checkmark$ & & & & $\checkmark$ & & & $\checkmark$ & & & & \\
\hline 3 & $\checkmark$ & $\checkmark$ & & $\checkmark$ & & $\checkmark$ & & & & & & \\
\hline 4 & & & & & & $\checkmark$ & & & & $\checkmark$ & & \\
\hline 5 & $\checkmark$ & & & & & & & & & & & \\
\hline 6 & & & & & & & & $\checkmark$ & & & & \\
\hline 7 & & & & & & & & $\checkmark$ & & & & \\
\hline 8 & $\checkmark$ & & & $\checkmark$ & & & & & & & & \\
\hline 9 & $\checkmark$ & & & & & & & & & & & \\
\hline 10 & $\checkmark$ & & & & & & & & & & & \\
\hline 11 & & & $\checkmark$ & & & & & $\checkmark$ & & $\checkmark$ & $\checkmark$ & $\checkmark$ \\
\hline 12 & $\checkmark$ & $\checkmark$ & & & & & $\checkmark$ & & & & & \\
\hline 13 & $\checkmark$ & & & & & & & & & & & \\
\hline 14 & $\checkmark$ & & & $\checkmark$ & & $\checkmark$ & $\checkmark$ & & & & & \\
\hline 15 & & & & & & & & & & & & \\
\hline 16 & $\checkmark$ & & & $\checkmark$ & & & & & & & & \\
\hline 17 & $\checkmark$ & & & & & & & & & & & \\
\hline 18 & $\checkmark$ & & $\checkmark$ & $\checkmark$ & & & $\checkmark$ & & & & & \\
\hline 19 & & & $\checkmark$ & & & & $\checkmark$ & & & & & \\
\hline 20 & & $\checkmark$ & & & & & & $\checkmark$ & & & & \\
\hline 21 & $\checkmark$ & & & & & & & $\checkmark$ & & & & \\
\hline 22 & $\checkmark$ & & & & & & & & & & & \\
\hline 23 & $\checkmark$ & & & & & & & $\checkmark$ & & & & \\
\hline
\end{tabular}

Table 9: Classifications and studies type of research.

\begin{tabular}{|l|l|l|l|l|l|l|l|l|l|l|l|l|l|l|l|l|l|l|l|l|l|l|l|}
\hline & 1 & 2 & 3 & 4 & 5 & 6 & 7 & 8 & 9 & 10 & 11 & 12 & 13 & 14 & 15 & 16 & 17 & 18 & 19 & 20 & 21 & 22 & 23 \\
\hline $\begin{array}{l}\text { Solution } \\
\text { proposal }\end{array}$ & $\checkmark$ & $\checkmark$ & $\checkmark$ & $\checkmark$ & $\checkmark$ & $\checkmark$ & & $\checkmark$ & $\checkmark$ & $\checkmark$ & $\checkmark$ & $\checkmark$ & $\checkmark$ & $\checkmark$ & & $\checkmark$ & $\checkmark$ & $\checkmark$ & $\checkmark$ & & $\checkmark$ & $\checkmark$ & $\checkmark$ \\
\hline $\begin{array}{l}\text { Validation } \\
\text { research }\end{array}$ & $\checkmark$ & $\checkmark$ & & & & $\checkmark$ & & $\checkmark$ & & $\checkmark$ & $\checkmark$ & & $\checkmark$ & & & & $\checkmark$ & $\checkmark$ & & & $\checkmark$ & $\checkmark$ & \\
\hline $\begin{array}{l}\text { Evaluation } \\
\text { research }\end{array}$ & & & & $\checkmark$ & & $\checkmark$ & & & & & & & $\checkmark$ & $\checkmark$ & $\checkmark$ & & & $\checkmark$ & $\checkmark$ & & & \\
\hline
\end{tabular}


Table 10: Summary of domain, results, sample and evaluation technique used in evaluation studies.

\begin{tabular}{|c|c|c|c|c|c|}
\hline ID & Domain & Result & $\begin{array}{c}\mathrm{N}^{0} \text { of } \\
\text { Participants }\end{array}$ & $\begin{array}{c}\mathrm{N}^{\mathbf{0}} \text { of } \\
\text { Documents }\end{array}$ & $\begin{array}{c}\text { Evaluation } \\
\text { technique used }\end{array}$ \\
\hline 5 & $\begin{array}{c}\text { Software } \\
\text { Engineering }\end{array}$ & $\begin{array}{c}\text { Students which used the } \\
\text { automatically generated MCs } \\
\text { presented an increased learning gain. }\end{array}$ & 59 & - & $\begin{array}{l}\text { CMs evaluated } \\
\text { by users }\end{array}$ \\
\hline 7 & Chemistry & $\begin{array}{l}\text { Students who used software to extract } \\
\text { concepts and relationships from the } \\
\text { text were able to build a CM faster. }\end{array}$ & 16 & - & $\begin{array}{l}\text { CMs evaluated } \\
\text { by users }\end{array}$ \\
\hline 14 & $\begin{array}{l}\text { Information } \\
\text { systems }\end{array}$ & $\begin{array}{l}\text { The capability to extract concepts and } \\
\text { relationships was evaluated in terms } \\
\text { of recall and precision (precision: } \\
72 \% \text {, recall: } 100 \% \text {, f-measure: } 84 \% \text { ). } \\
\text { Anaphoric resolution increased the } \\
\text { recall by } 9 \% \text {. }\end{array}$ & - & 65 & $\begin{array}{c}\text { Manually } \\
\text { Generated CMs } \\
\text { compared to } \\
\text { automatically } \\
\text { generated CMs } \\
\text { and CMs were } \\
\text { evaluated by } \\
\text { users }\end{array}$ \\
\hline 15 & $\begin{array}{l}\text { Information } \\
\text { Technology }\end{array}$ & $\begin{array}{l}\text { Users presented with CMs } \\
\text { automatically generated had similar } \\
\text { performance in selecting } \\
\text { studies when comparing to the expert } \\
\text { performance. }\end{array}$ & 22 & - & $\begin{array}{l}\text { Manually } \\
\text { generated CMs } \\
\text { compared to } \\
\text { automatically } \\
\text { generated CMs }\end{array}$ \\
\hline 16 & $\begin{array}{l}\text { Social } \\
\text { Service }\end{array}$ & $\begin{array}{l}\text { The experiments measure the } \\
\text { accuracy of conversion from } \\
\text { unstructured text into structured } \\
\text { concept maps and the accuracy of the } \\
\text { predictive function. The classifier } \\
\text { was evaluated in terms of acuraccy } \\
\text { recall and precision. (Recall: } 0.93 \% \text {, } \\
\text { precision: } 0.90 \% \text {. }\end{array}$ & - & 195 & $\begin{array}{l}\text { Manually } \\
\text { generated CMs } \\
\text { compared to } \\
\text { automatically } \\
\text { generated CMs }\end{array}$ \\
\hline 19 & Languages & $\begin{array}{c}\text { Students which used automatic } \\
\text { generated CMs presented gain in } \\
\text { reading comprehension and summary } \\
\text { writing skills }\end{array}$ & 107 & - & $\begin{array}{l}\text { CMs evaluated } \\
\text { by users }\end{array}$ \\
\hline 20 & $\begin{array}{c}\text { Not } \\
\text { specified }\end{array}$ & $\begin{array}{l}\text { The use of automatic generated CMs } \\
\text { allow users to substantially improve } \\
\text { their reading compreension skills in } \\
\text { terms of speed. }\end{array}$ & 16 & - & $\begin{array}{l}\text { Manually } \\
\text { generated CMs } \\
\text { compared to } \\
\text { automatically } \\
\text { generated CMs }\end{array}$ \\
\hline
\end{tabular}

In addition, the classification schema presents the algorithms and tools according to the techniques in which they are framed, they being linguistic or statistical. These techniques are part of the other two classification schema quadrants. The linguistic approach uses the rules of language to select concepts and extract relationships. The statistical technique assumes that the frequency of certain terms are indicators of their importance in a specific domain. Statistical techniques can still propose relationships based on the frequency of terms in the same sentence.

Based on the defined classification schema, we elaborate a graph summarizing the different paths to construct CM using NLP as described in the literature. The graph is presented in Figure 11. These paths were detected in the 23 studies selected in the mapping study. Each node of the graph represents an algorithm or tool used in the selected studies and their frequency. The edges represent the direction that was followed when using a set of algorithms or tools, as well as the different techniques. 


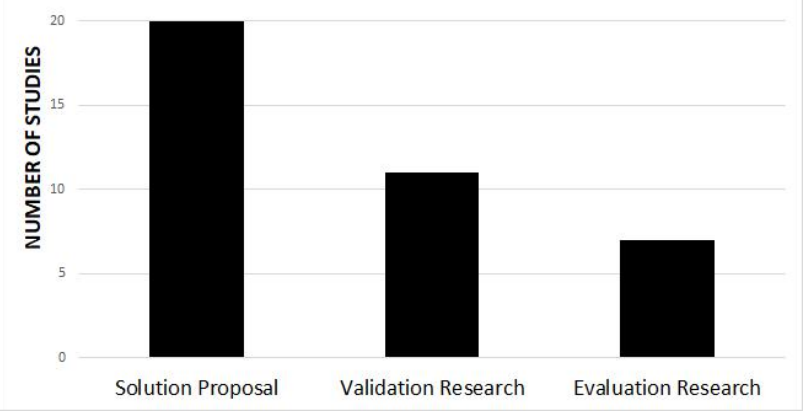

Figure 9: Number of studies in each type of study

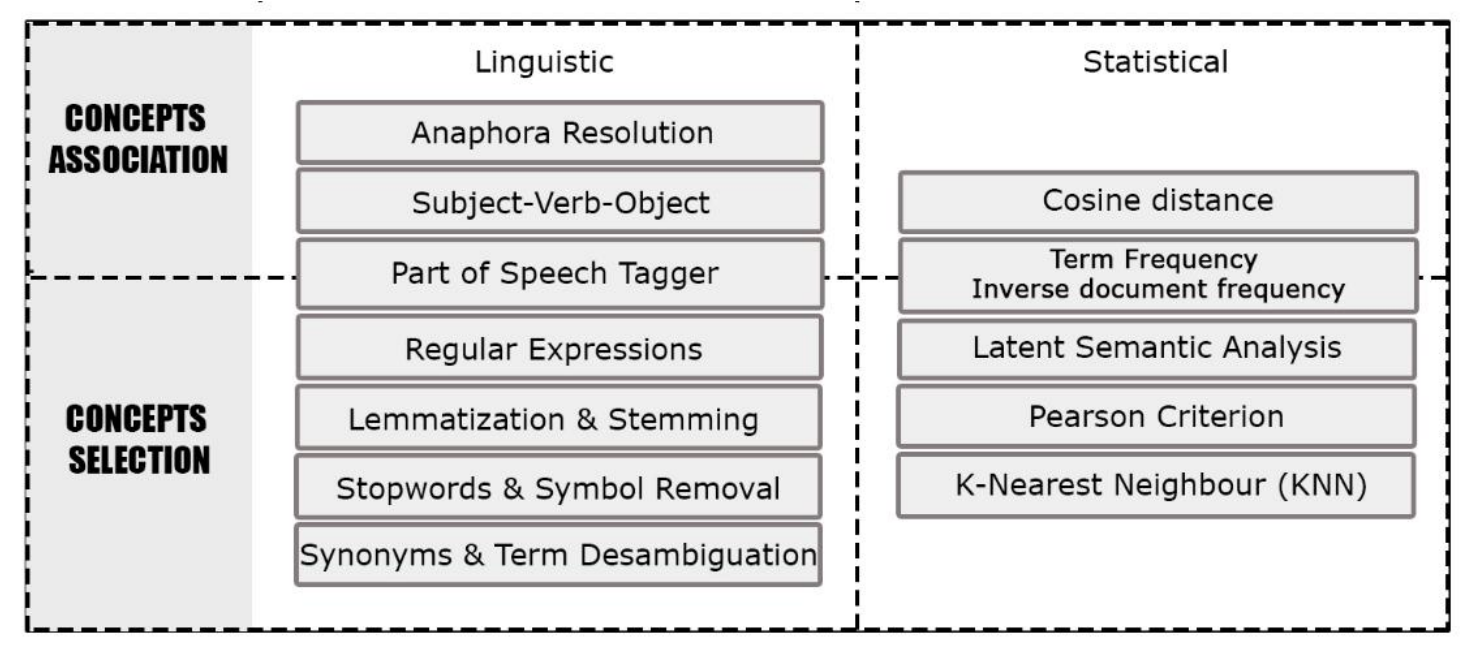

Figure 10: Classification schema to construction of CMs based in NLP.

The graph allows to start the construction of the CM from two distinct nodes, represented by the algorithms POS Tagger and TF-IDF. The first node is represented by a linguistic technique, in which case the linguistic technique most cited by the selected studies in the mapping is POS Tagger algorithm, which assigns tags to each word of a sentence identifying its grammatical class. The second node is represented by a statistical technique. The statistical algorithm most mentioned in the selected works in the mapping is the TF-IDF. This algorithm maps the most relevant terms by means of their frequency, taking into consideration the frequency of this same term in a set of documents belonging to the same domain. 


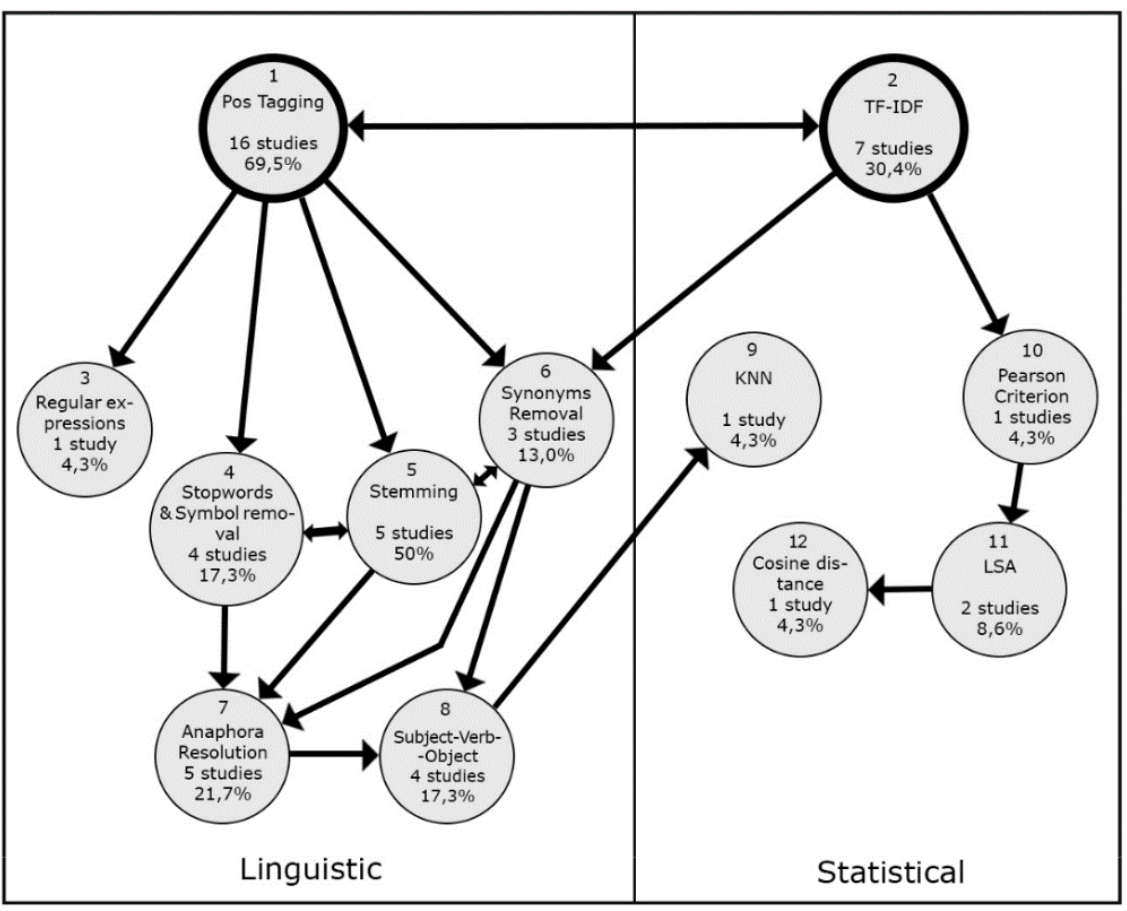

Figure 11: Graph of algorithms used in the studies selected.

Note that in the graph we enumerate each node to facilitate the exemplification of possible paths. In order to exemplify such solutions, we present below three real examples considering the different NLP techniques.

1. Statistical solution: It represents a solution from algorithms and tools considering only statistical techniques to reach the construction of CM from NLP. An example of statistical path to follow in graph is to consider nodes with sequence 2, 10, 11, 12.

2. Linguistic Solution: It represents a solution from algorithms and tools considering only linguistic techniques to reach the construction of CM from NLP. An example of linguistic path to follow in the graph is to consider nodes with sequence $1,3$.

3. Hybrid solution: Represents a solution by merging algorithms and tools considering both linguistic and statistical techniques to achieve the construction of CM from NLP. An example of hybrid path to follow in the graph is to consider nodes with sequence 1, 6, 8, 9 .

The paths presented in Figure 11 can be considered as possible solutions to generate CM. However, it is important to emphasize that the paths in the graph are those found only in the selected studies. Therefore, other paths may exist. It is noteworthy that, the paths presented in the graph shows that this sequence of techniques and tools were found in the 23 selected studies, and, it is believed that the path solutions to create a CM presented in the studies were validated by the authors of each study

\section{Results Discussion}

In this section we discuss findings and limitations of this mapping study.

CMs are playing an increasingly important role in several computing fields, e.g., Software Engineering, Ontologies and Programming Languages (Santos et al., 2017). They have been used for organizing and representing knowledge, facilitate knowledge examination, construction, com- 
parison, and reuse by users ranging from elementary graduate students to researchers. However, constructing CMs manually is a complex task. According to (Qasim et al., 2013), the automatic creation of CMs from text is a worthwhile research challenge. As shown in this mapping study, although the use of NLP to build CMs is recent, this approach has been considerably investigated in the last years.

With respect to the purpose for CM construction, educational purposes were most evidenced in the selected studies. According to Novak (Novak \& Cañas, 2008), concepts and relationships form the basis for learning and therefore CMs have been widely used as an educational tool in different contexts, either as a learning resource, means of evaluation, instructional organization, cognitive representation, elicitation or knowledge sharing.

From the selected studies, considering the analysis of the automation level for generation of CMs from NLP, both automatic and semi-automatic initiatives were identified. However, the initiatives considered automatic were the most used in the studies selected in this mapping. Such levels of $\mathrm{CM}$ generation consist of extracting the list of concepts from a text and determining the linking relationship that should connect to form meaningful propositions. According to Villalon and Calvo (Villalon \& Calvo, 2011), the automatic or semi-automatic extraction of CMs from text is also called Concept Map Mining (CMM).

With respect to the algorithms and tools used to extract CMs from text, there are several studies found in the literature proposing different approaches. The mapping study indicates that the most commonly used approaches are those that combine linguistic and statistical algorithms (as in (Caputo \& Ebecken, 2011; Qasim et al., 2013; Yang, 2015)). The linguistic algorithms vary according to the adopted language, making it very difficult to implement these approaches. To solve this problem, some studies suggest the linguistic processing tools to isolate the processing of speech parts for specific tools such as the Stanford NLP Parser or the Natural Language Toolkit (Qasim et al., 2013).

It is possible to establish, after conducting this study, that the automatic construction of CMs was presented in a positive way. Some advantages are presented in the studies, such as: stimulating knowledge specialist to explore new problem solving methods so as to increase the quality of their solutions; facilitate viewing and organizing of the flow of ideas to structure key concepts as well as improve their reading comprehension; assist in the teaching process; and generation of CMs with quickness, effectiveness, completeness and actuality.

Considering all aspects that selected the studies in this mapping study, a classification scheme was designed in order to present how NLP tools and algorithms could be employed to construct CMs. In addition, a Graph was elaborated to present different paths to construct CMs using NLP. Both the classification scheme and the Graph can be used to enumerate possible solutions or approaches considering the techniques, algorithms and tools used in the 23 studies selected by the mapping. This enumeration will serve mainly to guide researchers in the area to define the best approach to use to build a CM, as well as to define future works in the area.

In addition to the benefits about the use of CMs, we argue that they are also useful in secondary studies context, discussed as follows. Many researchers conducting secondary studies, as one of their first activities, need to read the abstracts to decide about their inclusion or exclusion. In some domains, such as clinical Medicine, Education, Psychology and Social Sciences, the review of abstracts is more than enough to determine its relevance (Kitchenham, 2004). How-ever, in Computer Science, there is no culture that determines the creation of structured abstracts in the studies. This becomes difficult to identify the relevance or not of the studies (Brereton, Kitchenham, Budgen, Turner, \& Khalil, 2007). Recent literature has provided evidence that unstructured and poorly written abstracts may compromise the selection activity (Brereton et al., 
2007; Kitchenham, Pearl Brereton, Owen, Butcher, \& Jefferies, 2008; Zhang \& Muhammad, 2011, 2012).

One potential solution to minimize such problem, experienced during a secondary study selection, is to promote the use of structured and graphical abstracts (Kitchenham et al., 2008). Since CMs can help in understanding a study, we have investigated the creation of graphical abstracts to support the selection activity in secondary studies using CMs (Felizardo, Souza, Hesae, Vijaykumar, \& Nakagawa, 2017; Santos et al., 2017). Graphical abstracts should enable reviewers to manipulate images to better understand the knowledge there represented (M. C. F. Oliveira \& Levkowitz, 2003), since analyzing data in graphical format requires less cognitive effort from the reviewer to extract information. In this context, CMs can be useful tools to summarize a complex structure of textual information, contributing in identifying the most relevant information in an article. The results of this mapping study, as well as the classification scheme and proposed Graph, will be used by us to support the construction of CMs based on NLP.

The main issues related to potential threats to validity are researchers' bias with respect to the study selection and data extraction steps. The study selection and data extraction steps were initially performed by just one of the authors, and thus some subjectivity could have been embedded. In order to reduce this subjectivity, the other three authors performed these same steps over the entire sample, so that all studies were reviewed by at least three researchers. The results of each reviewer were then compared in order to detect possible bias. An analysis of degree of conformance was performed to measure the level of agreement between the results obtained from the reviewers in the selection process.

Terminological problems in the search strings may have led to miss some primary studies. In order to minimize these problems, we performed previous manual review in the CMC proceedings in order to define the search string. Regarding internal validity, not all articles from all bases were collected, and so there may be some articles that deal with the subject, but were not addressed in the mapping. However, in this mapping study the main databases were used to reduce this threat. In addition, the inclusion of these articles does not invalidate the results obtained in this research, since other articles can be added in the classification scheme and graph to complement them.

\section{Conclusions}

This paper presented a systematic mapping study in the context of CMs and NLP. From the answers to research questions, a classification scheme was designed in order to present how NLP could be employed to construct CMs. From this classification scheme, a Graph was elaborated to present different paths to construct CMs using NLP. Six research questions were defined and addressed investigating the following aspects: (i) Distribution of the selected studies over the years; (ii) Purpose of CMs construction; (iii) Automation level that have been used in CMs construction; (iv) Techniques that have been used to construct CMs; (v) Tools that have been used to construct CMs; and (vi) Algorithms that have been used to construct CMs.

The contributions of this work are on making evident some aspects associated to the employment of NLP to construct CMs automatically and research efforts that can drive future research. In this context, we highlight the following conclusions: (i) educational purposes were most evidenced in the selected studies; (ii) initiatives considered automatic creation of CM were the most used; (iii) hybrid technique is the most used to construct CMs; and (iv) there are several studies found in the literature proposing different algorithms and tools to extract CMs from text.

In addition, we believe that a new researcher in this area can use the classification scheme and the graph created to become aware of the techniques currently being used. More experienced 
researchers can use the presented results to identify possible research gaps and direct their research to improve the techniques used to build CMs from text. Another possibility is to use the results of the mapping to support the CMs building in Intelligent Educational Systems. In (Zouaq et al., 2007) the authors showed how an intelligent tutoring system can benefit from the use of NPL techniques to generate CMs. In (Anohina-Naumeca \& Grundspenkis, 2012; Zouaq et al., 2007), CMs are described as a tool to improve teaching methods and knowledge management.

From the mapping results, as future work, we intend to explore how the automatic creation of CMs can assist in the studies selection in a secondary study (systematic literature review or systematic mapping study). Since CMs can help in the understanding of a study, our research group intends to investigate the creation of graphical abstracts to support the selection activity in secondary studies using CMs generated automatically.

\section{References}

Aguiar, C. Z., \& Cury, D. (2016a). Automatic construction of concept maps from texts. In 4th international conference on concept mapping (pp. 1-6). Tallinn, Estonia. [GS search]

Aguiar, C. Z., \& Cury, D. (2016b). A categorization of technological approaches to concept maps construction. In Latin american conference on learning objects and technology (laclo). Tallinn, Estonia. DOI: https://doi.org/10.1109/LACLO.2016.7751743 [GS search]

Anohina-Naumeca, A., \& Grundspenkis, J. (2012). Concept maps as a tool for extended support of intelligent knowledge assessment. In Proceedings of the 5th international conference on concept mapping: 5th international conference on concept mapping (p. 57-60). DOI: https://doi.org/10.1007/978-3-319-19773-9_2 [GS search]

Atapattu, T., Falkner, K., \& Falkner, N. (2015). Educational question answering motivated by question-specific concept maps. In Lecture notes in computer science (Vol. 9112, pp. 1322). DOI: https://doi.org/10.1007/978-3-319-19773-9_2 [GS search]

Brereton, P., Kitchenham, B. A., Budgen, D., Turner, M., \& Khalil, M. (2007). Lessons from applying the systematic literature review process within the software engineering domain. Journal of Systems and Software, 80(4), 571-583. DOI: https://doi.org/10.1016/j.jss.2006.07.009 [GS search]

Bui, D. D. A., Del Fiol, G., Hurdle, J. F., \& Jonnalagadda, S. (2016). Extractive text summarization system to aid data extraction from full text in systematic review development. Journal of Biomedical Informatics, 64, 265-272. DOI: https://doi.org/10.1016/j.jbi.2016.10.014 [GS search]

Cambria, E., \& White, B. (2014). Jumping NLP Curves: A Review of Natural Language Processing Research. IEEE Computational Intelligence Magazine, 9, 48-57. DOI: https://doi.org/10.1109/MCI.2014.2307227 [GS search]

Caputo, G. M., \& Ebecken, N. F. F. (2011). Concept map construction applying natural language processing on text extracted from e-commerce web pages. In 3rd world congress on nature and biologically inspired computing - (NABIC’11) (p. 409-414). Salamanca, Spain. DOI: https://doi.org/10.1109/NaBIC.2011.6089624 [GS search]

Ceausu, V., \& Després, S. (2007). Learning term to concept mapping through verbs: A case study. In CEUR workshop proceedings (Vol. 289). Whistler, Canada. [GS search]

Coffey, J. W., Reichherzer, T., Owsnick-Klewe, B., \& Wilde, N. (2012). Automated concept map generation from service-oriented architecture artifacts. In 5th international conference on concept mapping (Vol. 1, pp. 49-56). Valletta, Malta. [GS search]

Faily, S., Lyle, J., Paul, A., Atzeni, A., \& Blomme, D. (2012). Requirements Sensemaking Using Concept Maps. In International conference on human-centred software engineering (pp. 217-232). DOI: https://doi.org/10.1007/978-3-642-34347-6 13 [GS search] 
Felizardo, K., Souza, E., Hesae, S., Vijaykumar, N., \& Nakagawa, E. (2017). Analyzing the use of graphical abstracts to support study selection in secondary studies. In 20th workshop em engenharia de software experimental (ESELAW'17), (track experimental software engineering) within CIBSE'17 (20th ibero-american conference on software engineering), co-located with ICSE'17 (international conference on software engineering). [GS search]

Gurupur, V. P., Sakoglu, U., Jain, G. P., \& Tanik, U. J. (2014). Semantic requirements sharing approach to develop software systems using concept maps and information entropy: A Personal Health Information System example. Advances in Engineering Software, 70, 2535. DOI: https://doi.org/10.1016/j.advengsoft.2014.01.001 [GS search]

Jalali, S., \& Wohlin, C. (2012). Systematic literature studies: Database searches vs. backward snowballing. In $6^{\text {th }}$ international symposium on empirical software engineering and measurement (ESEM'12) (pp. 29-38). ACM. DOI: https://doi.org/10.1145/2372251.2372257 [GS search]

Junqueira, M. M., Silva, Patrícia, A., \& Maximiano, F. A. (2014). A methodology to change student-written texts into representative concept maps. In 6th international conference in concept mapping (pp. 7-14). Santos, Brazil. [GS search]

Jurafsky, D., \& Martin, J. H. (2009). Speech and language processing : an introduction to natural language processing, computational linguistics, and speech recognition. Upper Saddle River: Pearson/Prentice Hall, 2009. [GS search]

Kao, A., \& Poteet, S. R. (2007). Natural language processing and text mining. London: springerVerlag. [GS search]

Katagall, R., Dadde, R., Goudar, R. H., \& Rao, S. (2015). Concept mapping in education and semantic knowledge representation: an illustrative survey. Procedia Computer Science, 48, 638-643. DOI: https://doi.org/10.1016/j.procs.2015.04.146 [GS search]

$\mathrm{Ke}, \mathrm{Z}$. (2013). Research on the approach of automatic construct concept maps from online course. Information Technology Journal, 12(24), 8020-8024. DOI: https://doi.org/10.3923/itj.2013.8020.8024 [GS search]

Kitchenham, B. (2004). Procedures for performing systematic reviews. Keele, UK, 33 (TR/SE0401), 28. [GS search]

Kitchenham, B., \& Charters, S. (2007). Guidelines for performing systematic literature reviews in software engineering (Vol. 2; Tech. Rep.). Durham, UK: Keele University and Durham University Joint Report. [GS search]

Kitchenham, B., Pearl Brereton, O., Owen, S., Butcher, J., \& Jefferies, C. (2008). Length and readability of structured software engineering abstracts. IET Software, 2(1), 37. DOI: https://doi.org/10.1049/iet-sen:20070044 [GS search]

Kof, L., Gacitua, R., Rouncefield, M., \& Sawyer, P. (2007). Concept Mapping as a Means of Requirements Tracing. In The journal of nursing education (Vol. 46, pp. 232-234). DOI: https://doi.org/10.1109/MARK.2010.5623813 [GS search]

Kowata, J. H., Cury, D., \& Boeres, M. C. S. (2010a). Concept maps core elements candidates recognition from text. In 4th international conference on concept mapping (pp. 120-127). Viña del Mar, Chile. [GS search]

Kowata, J. H., Cury, D., \& Boeres, M. C. S. (2010b). A review of semi-automatic approaches to build concept maps. In 4th int. conference on concept mapping (pp. 40-48). Viña del Mar, Chile. [GS search]

Martin-Rodilla, P., \& Gonzalez-Perez, C. (2016). Extracting static and dynamic model elements from textual specifications in humanities. In 4th international conference on technological ecosystems for enhancing multiculturality (p. 949-955). Salamanca,Spain. DOI: https://doi.org/10.1145/3012430.3012631 [GS search]

Molleri, J. S., Petersen, K., \& Mendes, E. (2016). Survey guidelines in software engineering. In 10th international symposium on empirical software engineering and measurement - 
(ESEM'16) (pp. 1-6). Ciudad Real, Spain. DOI: https://doi.org/10.1145/2961111.2962619 [GS search]

Novak, J. D., \& Cañas, A. J. (2008). The theory underlying concept maps and how to construct and use them (Tech. Rep.). Pensacola, USA: Florida Institute for Human and Machine Cognition. [GS search]

Novak, J. D., \& Cañas, A. J. (2006). The origins of the concept mapping tool and the continuing evolution of the tool. Information Visualization, 5(3), 175-184. DOI: https://doi.org/10.1057\%2Fpalgrave.ivs.9500126 [GS search]

Nugumanova, A., Mansurova, M., Alimzhanov, E., Zyryanov, D., \& Apayev, K. (2015). Automatic generation of concept maps based on collection of teaching materials. In 4th international conference on data management technologies and applications (pp. 248-254). Colmar, France. DOI: https://doi.org/10.5220/0005554702480254 [GS search]

O’Leary, D. E. (1998, March). Enterprise knowledge management. Computer, 31(3), 54-61. DOI: https://doi.org/10.1109/2.660190 [GS search]

O’Leary, D. E., \& Studer, R. (2001, Jan). Knowledge management: an interdisciplinary approach. IEEE Intelligent Systems, 16(1), 24-25. DOI : https://doi.org/10.1109/MIS.2001.912381 [GS search]

Oliveira, A., Pereira, F. C., \& Cardoso, A. (2001). Automatic reading and learning from text. In International symposium on artificial intelligence - (ISAI’01) (pp. 1-12). Fort Panhala, India. [GS search]

Oliveira, M. C. F., \& Levkowitz, H. (2003). From visual data exploration to visual data mining: A survey. IEEE Transactions on Visualization and Computer Graphics, 9(3), 378-394. DOI: https://doi.org/10.1109/TVCG.2003.1207445 [GS search]

Olney, A. M., Cade, W. L., \& Williams, C. (2011). Generating concept map exercises from textbooks. In 6th workshop on innovative use of NLP for building educational applications (p. 111-119). Portland, USA. [GS search]

Petersen, K., Feldt, R., Mujtaba, S., \& Mattsson, M. (2008). Systematic mapping studies in software engineering. In 12th international conference on evaluation and assessment in software engineering - ease (pp. 68-77). [GS search]

Qasim, I., Jeong, J.-W., Heu, J.-U., \& Lee, D.-H. (2013). Concept map construction from text documents using affinity propagation. Journal of Information Science, 39, 719-736. DOI: https://doi.org/10.1177\%2F0165551513494645 [GS search]

Richardson, R., \& Fox, E. A. (2005). Using concept maps in ndltd as a cross-language summarization tool for computing - related etds monolingual etd experiment. In 5th ACMIEEE joint conference on digital libraries jcdl (p. 711). Denver, USA. [GS search]

Rueda, U., Arruarte, A., Elorriaga, J., \& Herran, E. (2009). A contour-based segmentation algorithm for triangle meshes in 3d learning the attachment theory with the CM-ED concept map editor. Computers \& Education, 52, 460-469. DOI: https://doi.org/10.1016/j.cag.2015.04.003 [GS search]

Santos, V., Souza, E. F., Felizardo, K. R., \& Vijaykumar, N. L. (2017). Analyzing the use of concept maps in computer science: Systematic mapping study. Informatics in Education. Accepted for Publication. DOI: http://dx.doi.org/10.15388/infedu.2017.13 [GS search]

Silva, C. P., Morais, J. M., \& Monteiro, D. C. (2014). Text2mark: A text mining tool in the aid of knowledge representation. In International conference on intelligent systems design and applications, isda (p. 236-241). Okinawa, Japan. DOI: https://doi.org/10.1109/ISDA.2013.6920741 [GS search]

Valerio, A., Leake, D. B., \& Cañas, A. J. (2012). Using automatically generated concept maps for document understanding: a human subjects experiment. In 5th international conference on concept mapping (Vol. 2, p. 438-445). Valleta, Malta. [GS search] 
Villalon, J., \& Calvo, R. A. (2011). Concept maps as cognitive visualizations of writing assignments. Educational Technology and Society, 14(3), 16-27. [GS search]

Wang, W. M., Cheung, C. F., Lee, W. B., \& Kwok, S. K. (2008). Mining knowledge from natural language texts using fuzzy associated concept mapping. Information Processing and Management, 44(5), 1707-1719. DOI: https://doi.org/10.1016/j.ipm.2008.05.002 [GS search]

Wang, W. M., Cheung, C. F., Lee, W. B., \& Kwok, S. K. (2009). A computational narrative construction method with applications in organizational learning of social service organizations. Expert Systems with Applications, 36(4), 8093-8102. DOI: https://doi.org/10.1016/j.eswa.2008.10.035 [GS search]

Wieringa, R., Maiden, N., Mead, N., \& Rolland, C. (2005, December). Requirements engineering paper classification and evaluation criteria: A proposal and a discussion. Journal Requirements Engineering, 11(1), 102-107. DOI: https://doi.org/10.1007/s00766-0050021-6 [GS search]

Williams, C. B., Moore, J. P., Johri, A., Pierce, S. R., \& North, C. (2012). Advancing Personalized Learning Via an Adaptive concept map. In Annual conference (ASEE'12) (p. 12). [GS search]

Yang, Y. F. (2015). Automatic scaffolding and measurement of concept mapping for EFL students to write summaries. Educational Technology and Society, 18(4), 273-286. [GS search]

Yoon, W. C., Lee, S., \& Lee, S. (2014). Burst analysis of text document for automatic concept map creation. In 27th international conference on industrial engineering and other applications of applied intelligent systems - IEA/AIE (pp. 407-416). Kaohsiung, Taiwan. DOI: https://doi.org/10.1007/978-3-319-07467-2 43 [GS search]

Zack, M., \& Serino, M. (2000). Knowledge management and collaboration technologies. In (p. 303-315). Butterworth. [GS search]

Zhang, H., \& Muhammad, A. (2012). Systematic reviews in software engineering: An empirical investigation. Information and Software Technology, 5(7), 1341-1354. DOI: https://doi.org/10.1016/j.infsof.2012.09.008 [GS search]

Zhang, H., \& Muhammad, P., A. B. Tell. (2011). Identifying relevant studies in software engineering. Information and Software Technology, 53(1), 625-637. DOI: https://doi.org/10.1016/j.infsof.2010.12.010 [GS search]

Zouaq, A., \& Nkambou, R. (2008). Building domain ontologies from text for educational purposes. IEEE Transactions on Learning Technologies, 1(1), 49-62. DOI: https://doi.org/10.1109/TLT.2008.12 [GS search]

Zouaq, A., Nkambou, R., Frasson, C., Wilson, D., \& Sutcliffe, G. (2007). Document semantic annotation for intelligent tutoring systems : a concept mapping approach. In Flairs conference (pp. 380-385). Florida, United States. [GS search] 